\title{
Picosecond-laser processing of stainless steel for fabricating superhydrophobic surfaces
}

\author{
${ }^{1}$ Dupliak I., ${ }^{1}$ Yuchen Liang, ${ }^{1}$ Guozhu Yan, ${ }^{1 *}$ Fenping Li, ${ }^{2}$ Ivaniuk K. and \\ ${ }^{3}$ Xiaogang Li \\ ${ }^{1}$ Wenzhou University Institute of Laser and Optoelectronic Intelligent \\ Manufacturing, Ocean Science and Technology Innovation Park, No. 19 Binhai \\ 3rd Road, Yongxing Street, Longwan District, Wenzhou, Zhejiang, China \\ ${ }^{2}$ Lviv Polytechnic National University, 12 S. Bandera Street, 79013 Lviv, Ukraine. \\ ${ }^{3}$ Lyncwell Innovation Intelligent System (Zhejiang) Co., Ltd., Ocean Science and \\ Technology Innovation Park, No. 19 Binhai 3rd Road, Yongxing Street, Longwan \\ District, Wenzhou, Zhejiang, China
}

Received: 11.08 .2020

\begin{abstract}
We create a high-precision surface microstructure at the surfaces of SAE 304 stainless steel plates, using picosecond-laser pulses with high repetition rates. The surfaces acquire cross-groove patterns due to a line-by-line laser ablation technology. The wettability of the microstructured metal surface is studied. The microstructured surface provides a superhydrophobicity with good anticorrosion and antibacterial properties, which can extend significantly the scope of applications of the underlying material.
\end{abstract}

Keywords: picosecond lasers, superhydrophobicity, stainless steel, wettability

UDC: 535.21

\section{Introduction}

One of the key areas of modern materials science is surface modification of original materials using chemical, physical or some other modification types [1,2]. These modifications enable obtaining required surface parameters without losing the integrity of structure of the material and its inherent properties. One of the modification directions is changing wettability of microstructured metal surfaces. It has been frequently reported in the recent decades [3-9] due to vide range of possible applications, e.g. anti-corrosion and anti-bacterial coating, oil-water separation or liquid transportation. It is known that a switch of surface properties from hydrophilic to hydrophobic ones can be achieved owing to significant increase of surface area. In its turn, this can be done when highly precise microstructures are created on the surface. The classical techniques used to fabricate microstructures are thermal oxidation, chemical-vapour deposition, plasma spraying, electrochemical machining, electrochemical deposition, sol-gel method, etc. [8, 10, 11].

Most of these techniques manifest serious disadvantages such as, e.g., long processing time, a necessity in vacuum or inert atmospheres, and usage of environmentally dangerous consumables. Moreover, they often require significant manufacturing times, whereas the superhydrophobic surfaces thus obtained turn out to be costly. The above shortcomings make these techniques inefficient whenever a full-scale production is meant. As a consequence, alternative techniques for fabrication of microstructures are in great need for different manufacturing sectors such as microelectronics, aeronautics, electric engineering, medicine and many others.

One of the most promising techniques for creating periodical microstructures on metal surfaces is high-precision laser ablation based upon short or ultra-short laser pulses. Although this

${ }^{*}$ Corresponding author: 1fp@wzu.edu.cn

Ukr. J. Phys. Opt. 2020, Volume 21, Issue 4 
method has been studied in great detail (see, e.g., Refs. [6-9, 12-14]), it still represents a challenging problem. One of the key issues hindering its applications in any full-scale manufacturing is a long-time processing. As an example, Ref. [12] claims a successful wettability change from hydrophilic to superhydrophobic, although this requires several hours for lowtemperature annealing. Moreover, the processing speed has been fixed at $0.1 \mathrm{~mm} / \mathrm{s}$, which also makes laser processing more time-consuming and expensive. The authors of the work [13] have attempted to increase the processing speed and simplify the process. This has led to superhydrophobic surfaces with the contact angles less than $150^{\circ}$ due to insufficient quality of the microstructures. The method reported in Ref. [14] has suggested separate line-like structures rotated by $60^{\circ}$ with respect to each other, resulting in a triangular-like geometry. However, this technique requires a working $x-y-z$ stage with highly precise rotating control. Furthermore, the rotating $\mathrm{x}-\mathrm{y}-\mathrm{z}$ stage can complicate the process of laser-beam focusing, which again could impose less applicability of the technique in full-scale manufacturing.

In the present work, we develop an easy-to-make, cheap, fast, efficient, safe and environmentally friendly technique for fabricating superhydrophobic surfaces. It involves a picosecond laser to achieve good values of the contact angle. As a result, we create highly precise and deep enough grooves on a surface and minimize the time needed for the processing.

\section{Experimental}

\subsection{Method for fabricating superhydrophobic surfaces}

We fabricated a superhydrophobic surface of the stainless steel using a picosecond-laser ablation method. A line-by-line cross scanning was performed in order to form a cross-groove pattern. The ablation process was conducted in the air. Then the surface was sprayed with a modifier (a nanoprotector from EYKOSI). We let it sit for $1 \mathrm{~min}$ until it had volatilized. The precursor material was an austenitic stainless steel SAE 304. It is one of the most widely used stainless steels, having high resistance to short-time heat treatment. Our samples were prepolished and had a squared shape of plates $\sim 50 \times 50 \times 0.8 \mathrm{~mm}^{3}$. A crossed microgroove pattern was fabricated owing to programmed movement of a sample-mounted nanopositioning $\mathrm{x}-\mathrm{y}-\mathrm{Z}$ working stage (a Q-545 stage from Physik Instruments Industries, Germany).
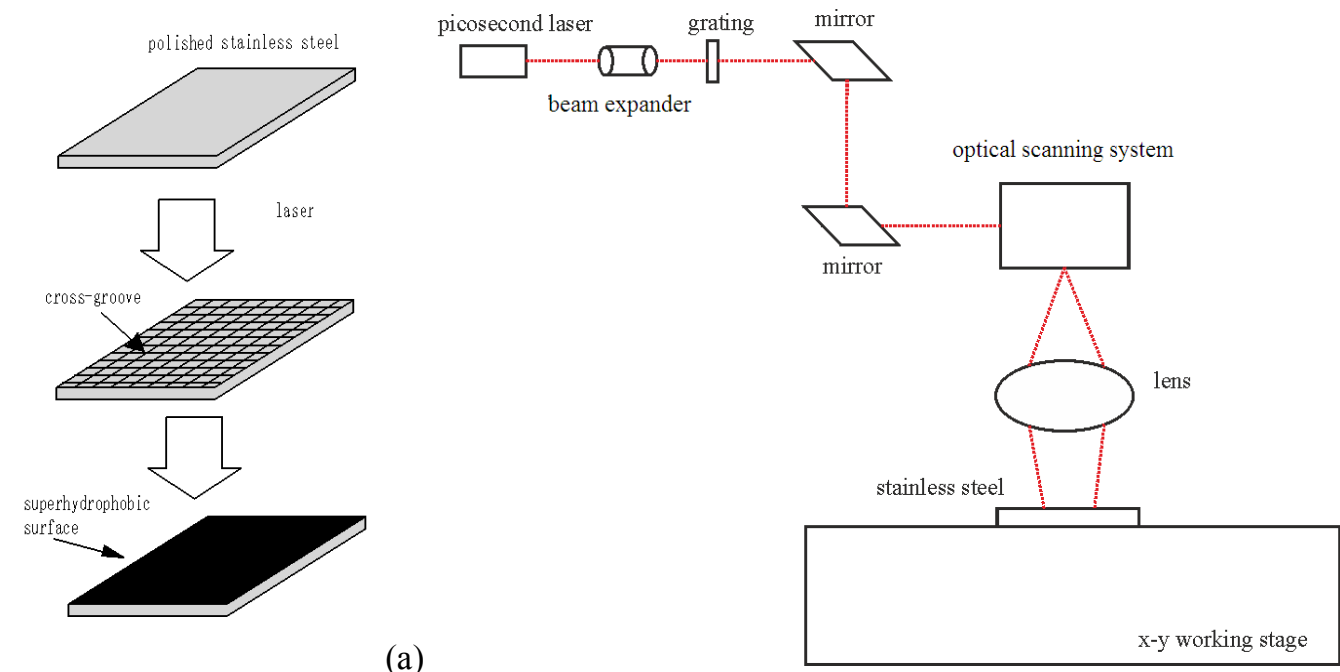

Fig. 1. Principal schemes of a process used to manufacture superhydrophobic surfaces (a) and experimental setup used to treat metal surfaces with a picosecond-laser radiation (b). 
The shape of a scanning path was cross-line, as shown in Fig 1a. We used an optical radiation generated by a picosecond laser system (MicroMach2040, Xi'an Micromach Technology Co., Ltd). It was fed into a scanning system through a beam expander and a grating (see Fig. 1b). After adjusting transmitting direction by the scanning system, it was focused at the stainless-steel surface. Laser microgrooving was performed under the following technical conditions: the pulse width $10 \mathrm{ps}$, the pulse repetition frequency $10 \mathrm{kHz}$, the laser power density $5.72 \times 10^{5} \mathrm{~W} / \mathrm{cm}^{2}$, the equivalent laser fluence $1.43 \mathrm{~J} / \mathrm{cm}^{2}$ per pulse, and the central optical wavelength $515 \mathrm{~nm}$. The laser scanning speed was fixed at $10 \mathrm{~mm} / \mathrm{s}$. The processing parameters optimal for achieving the superhydrophobic surface were optimized by changing the scanning spacing and the laser fluence.

\subsection{Characterization of microstructures}

Surface morphology of the laser-textured stainless steel SAE 304 was characterized with a laser scanning confocal microscope (OLYMPUS, OSL4100). The cross-groove pattern had a periodical structure kept with a high precision, which allowed us to consider the overall structure of the surface as a set of periodic elements repeated along both longitudinal and transverse directions (see Fig. 2a). The basic element of the structure was a square with the side length $\sim 30 \mu \mathrm{m}$, while the distance between the adjacent elements along the $\mathrm{x}$ and $\mathrm{y}$ directions was also equal to $\sim 30 \mu \mathrm{m}$ (see Fig. 2b). Notice that a hierarchical microstructure of the surface with low surface energy is a key factor needed for superhydrophobic property to exist. This can be explained by a standard Cassie contact model [9], according to which a water droplet only contacts with a peak of microstructure, thus forming an extremely discontinuous contact interface.

A presence of deformations in a lower part of the groove should also be noted. They are caused by re-condensation of the material from side walls (see Fig. 3). However, a non-smooth geometry of

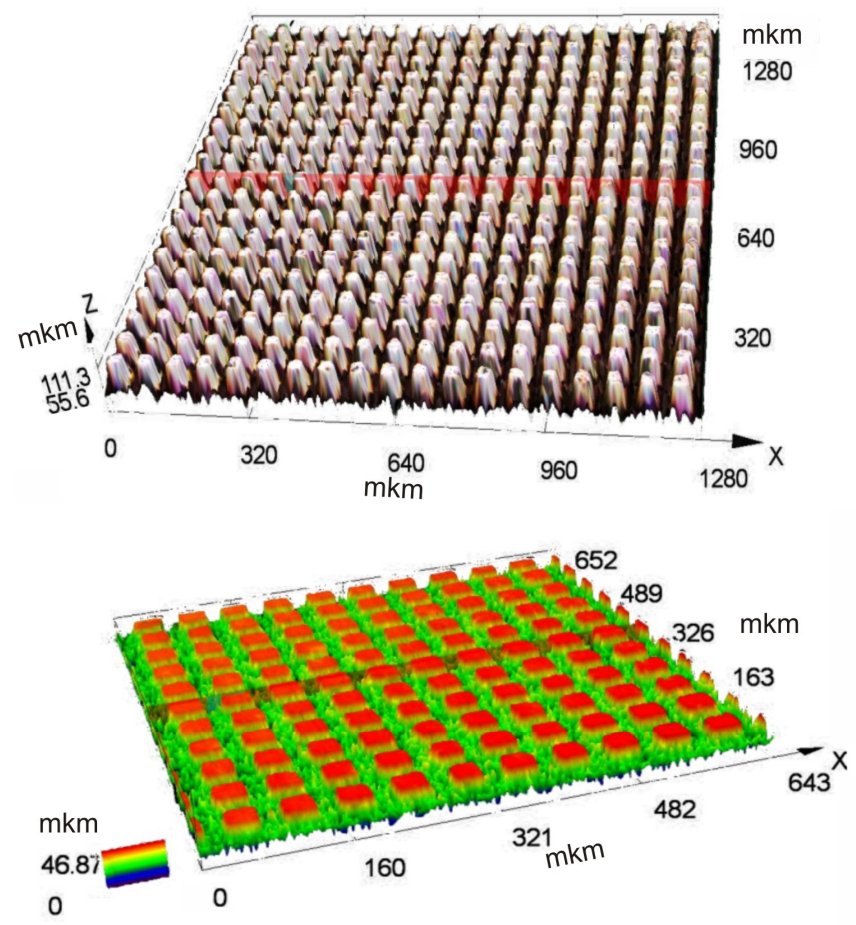

(a)

(b)

Fig. 2. Characterization of surface morphology of our laser-textured stainless steel SAE 304: 3D height (a) and $3 \mathrm{D}$ colour (b) visualizations.

Ukr. J. Phys. Opt. 2020, Volume 21, Issue 4 
the groove bottom has no effect on the resulting contact angle, because this part of the surface has no point of contact with a liquid. On the other hand, there is some material condensed at each 'pillar' (see Fig. 4a). This indicates excessive build-up of heat, which is a caused by picosecond-laser micromachining. Therefore, it is a presence of molten material caused by this reason that limits the geometrical precision of the entire technological process. Furthermore, some ripples, holes and spikes with hardly detectable sizes can be formed on the surface of the 'pillars' (see Fig. 4).

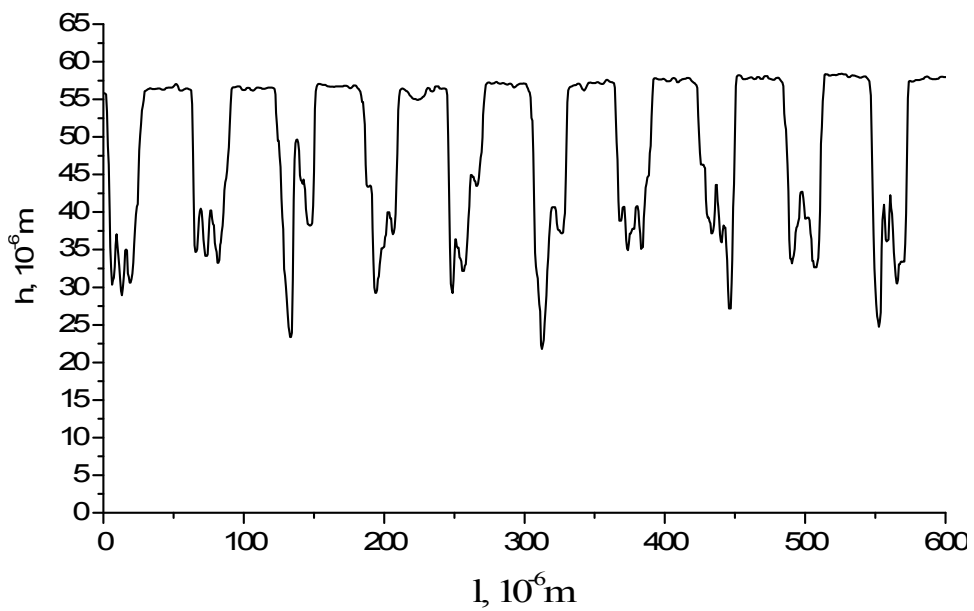

Fig. 3. Linear section profile of our laser-textured stainless steel SAE 304.
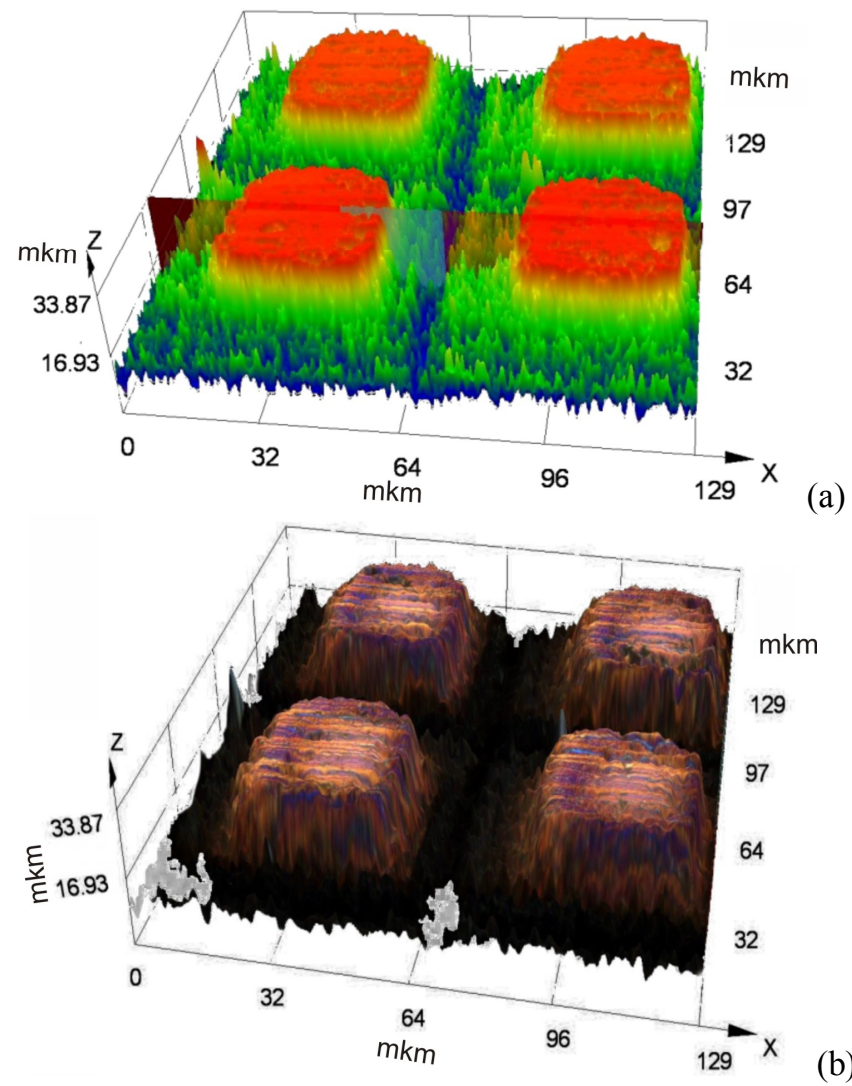

(b)

Fig. 4. A more detailed characterization of surface morphology of our laser-textured stainless steel SAE 304 (cf. with Fig. 2): 3D colour (a) and 3D height (b) visualizations.

Ukr. J. Phys. Opt. 2020, Volume 21, Issue 4 
According to the theory of 'lotus effect' [15], the nanostructures similar to those seen in Fig. 2 and Fig. 4 play an important role in the wettability of surfaces. According to Ref. [15], only combination of micro-scale pillars and nano-scale structures can cause large contact angles needed for forming superhydrophobic properties of the surfaces.

In order to study superhydrophobicity of our surface, the steel samples were examined with a sessile-drop method, using a video-monitored optical contact-angle measuring system (Data Physics OCA15EC, Germany). Each sample was tested using $5 \mu \mathrm{L}$ distilled-water droplets. Software for a low-band axisymmetric drop-shape analysis (LBADSA) was employed. The microstructured surface obtained in the manner described above indeed manifests the superhydrophobic properties (see Fig. 5). To be more specific, we have achieved the degree of the surface hydrophobicity that corresponds to the contact angle $166.5^{\circ} \pm 2.5^{\circ}$ (see Fig. $5 b$ ).
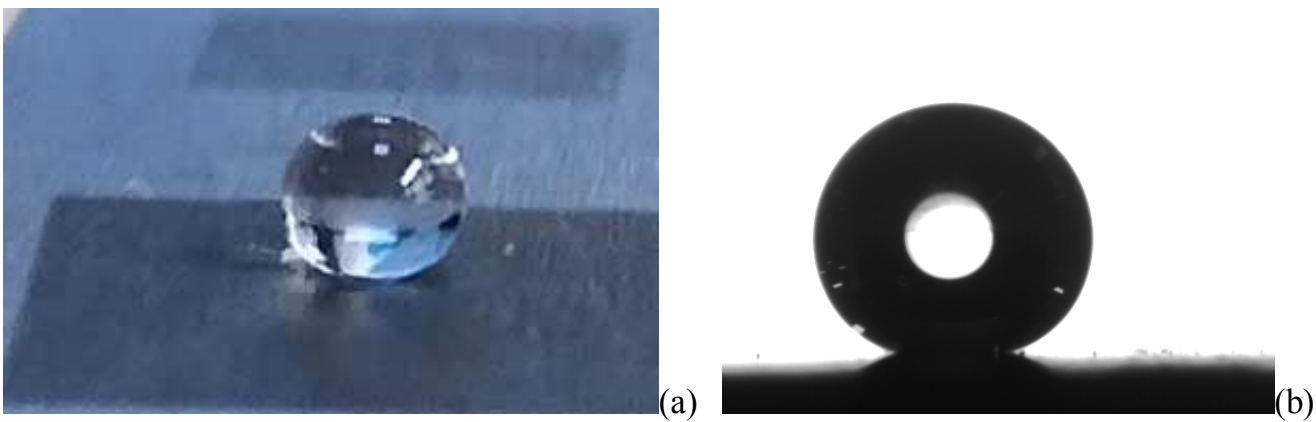

Fig. 5. Image of a distilled-water droplet on our superhydrophobic surface (a) and a corresponding image obtained with the optical contact-angle measuring system (b).

Since the laser-scanning speed applied in our process is $10 \mathrm{~mm} / \mathrm{s}$ and the laser passes only once per each groove, our technique for making superhydrophobic surfaces turns out to be extremely high-speed. The technique requires no additional chemical pre-treatment, which makes it environmentally friendly. It is evident that our technique is very simple in the sense that it does not require inert atmospheres or vacuum. Moreover, spraying a modifier takes much less time than soaking a chemical solution, which improves greatly the production efficiency. Note that the superhydrophobic properties acquired by the stainless steel produce also a useful side effect: high anticorrosion and antibacterial properties. Moreover, this reduces friction which can also extend the potentials of the material.

Finally, we are to stress that the results depicted in Fig. 5a, b demonstrate that the micropatterns and the specific geometry created on the surface by the laser processing play a major role for improving the degree of hydrophobicity. An optimal combination of micro- and nanostructures present on the surface can facilitate further improving a degree of hydrophobicity of that surface.

\section{Conclusion}

A superhydrophobic surface with the contact angle as large as $166.5 \pm 2.5^{\circ}$ has been obtained with the method of microgrooving by the picosecond laser. Laser scanning speed has been equal to $10 \mathrm{~mm} / \mathrm{s}$, thus enabling one to achieve a high enough production speed, $2.7 \mathrm{~mm}^{2} / \mathrm{s}$. The surface requires no pre-treatment, which simplifies our technology. The line-by-line laser ablation technique adopted in this work represents a cheap, fast, easy, efficient, safe and environmentally friendly method for fabricating superhydrophobic surfaces. Indeed, a high processing speed and no need in inert atmosphere enable production of large volumes of superhydrophobic surfaces in 
minimal time and at low resource cost. Hence, our technique based on the microstructures built on working surfaces can be used in the modern full-scale manufacturing processes.

\section{Acknowledgement}

This work is supported by the National Key Research and Development Program (2018YFB1108000) and the Wenzhou Key Science and Technology Project (ZG2019031).

\section{References}

1. Ivanov Y F, Gromov V E and Konovalov S V, 2009. Electron-beam modification of the pearlite steel. Arab. J. Sci \& Engin. 34: 219-229.

2. Konovalov S V, Kormyshev V E, Gromov V E, Ivanov Yu F, Kapralov E V and Semin A P, 2016. Formation features of structure-phase states of $\mathrm{Cr}-\mathrm{Nb}-\mathrm{C}-\mathrm{V}$ containing coatings on martensitic steel. J. Synch. Investig. 10: 1119-1124.

3. Zhang E, Wang Y, Lv T, Li L, Cheng Z and Liu Y, 2015. Bio-inspired design of hierarchical PDMS microstructures with tunable adhesive superhydrophobicity. Nanoscale. 7: 6151-6158.

4. Esmailzadeh S, Khorsand S, Raeissi K and Ashrafizadeh F, 2015. Microstructural evolution and corrosion resistance of super-hydrophobic electrodeposited nickel films. Surf. Coat. Techn. 283: 337-346.

5. Cai Y, Chang W, Luo X and Qin Y, 2019. Superhydrophobicity of microstructured surfaces on zirconia by nanosecond pulsed laser. J. Microman. 2: 5-14.

6. Pan Q, Cao Y, Xue W, Zhu D and Liu W, 2019. Picosecond laser-textured stainless steel superhydrophobic surface with an antibacterial adhesion property. Langmuir. 35: 11414-11421.

7. Long J, Zhong M, Zhang H and Fan P, 2015. Superhydrophilicity to superhydrophobicity transition of picosecond laser microstructured aluminum in ambient air. J. Colloid. Interface. Sci. 441: 1-9.

8. Jiang T, Koch J, Unger C, Fadeeva E, Koroleva A, Zhao Q and Chichkov B N, 2012. Ultrashort picosecond laser processing of micro-molds for fabricating plastic parts with superhydrophobic surfaces. Appl. Phys. A. 108: 863-869.

9. Yong J, Chen F, Yang Q, Farooq U and Hou X, 2015. Photoinduced switchable underwater superoleophobicity-superoleophilicity on laser modified titanium surfaces. J. Mat. Chem. A. 3: 10703-10709.

10. Di Giulio S, Faraldi P, Russo N, Fino D, Saracco G and Specchia V, 2009. Photo-catalytic coating of polystyrene for household cooling appliances with self cleaning surfaces. J. Appl. Electrochem. 39: 2265-2273.

11. Huang L, Lau S P, Yang H Y, Leong E S P, Yu S F and Prawer S, 2005. Stable superhydrophobic surface via carbon nanotubes coated with a $\mathrm{ZnO}$ thin film. J. Phys. Chem. B. 109: 7746-7748.

12. Chun D M, Ngo C V and Lee K M, 2016. Fast fabrication of superhydrophobic metallic surface using nanosecond laser texturing and low-temperature annealing. CIRP Annals. 65: $519-522$.

13. Ta V D, Dunn A, Wasley T J, Li J, Kay R W, Stringer J, Smith P J, Esenturk E, Connaughton C and Shephard J D, 2016. Laser textured superhydrophobic surfaces and their applications for homogeneous spot deposition. Appl. Surf. Sci. 365: 153-159.

14. Milles S, Soldera M, Voisiat B and Lasagni AF, 2019. Fabrication of superhydrophobic and ice-repellent surfaces on pure aluminium using single and multiscaled periodic textures. Sci. Rep. 9: 13944. 
15. Cheng Y T, Rodak D E, Wong C A and Hayden C A, 2006. Effects of micro- and nanostructures on the self-cleaning behaviour of lotus leaves. Nanotechnol. 17: 1359.

Dupliak I., Yuchen Liang, Guozhu Yan, Fenping Li, Ivaniuk K. and Xiaogang Li. 2020. Picosecond-laser processing of stainless steel for fabricating superhydrophobic surfaces. Ukr.J.Phys.Opt. 21: 170 - 177. doi: 10.3116/16091833/21/4/170/2020

Анотація. Використовуючи пікосекундні лазерні імпульси з високою швидкістю повторення, ми створили високоточну мікроструктуру на поверхнях пластинок 3 нержавіючої сталі SAE 304. Завдяки технології порядкової лазерної аблячї поверхням надано форму поперечних канавок. Вивчено змочуваність мікроструктурованих металевих поверхонь. Мікроструктурована поверхня забезпечує надгідрофобність з хорочими антикорозійними та антибактеріальними властивостями, щзо може значно розширити сфери застосування основного матеріалу. 